\title{
Infección rinosinusal por Scedosporium apiospermum en un hospedero inmunocompetente
}

\author{
Leonardo Chanqueo C., Catalina Gutiérrez R., Cecilia Tapia P., \\ Víctor Silva V., Leopoldo Razeto W. y Carlos Misad S.
}

\section{Scedosporium apiospermum rhinosinusal infection in an immunocompetent host}

Scedosporium species can cause colonization, superficial and deep localized infection or systemic disease, especially in immunocompromised hosts. We report a case of localized infection due to Scedosporium apiospermum in a 47 year old woman, with previous nasal surgery. She consulted for recurrent mucopurulent post-nasal discharge not responding to antibiotics. Computed tomography showed opacification of right maxillary sinus. Surgery was performed to removed abnormal tissue from sinus; biopsy revealed chronic sinusitis with aggregate of tightly packed hyphae suggestive of filamentous fungi. The microbiology fungal culture reported Scedosporium apiospermum.

Key words: Scedosporium apiospermum, paranasal fungus balls, antifungal agents.

Palabras clave: Scedosporium apiospermum, bola fúngica paranasal, agentes antifúngicos.

\section{Introducción}

$\mathrm{L}$ a incidencia y prevalencia de rinosinusitis fúngica se ha incrementado en los últimos años, así como también la diversidad de los patógenos involucrados. Se estima que $10 \%$ de los pacientes sometidos a cirugía rinosinusal tienen hallazgo de rinosinusitis fúngica $\mathrm{y}$, si se consideran las sinusitis crónicas maxilares, la bola fúngica se encuentra en $\sim 13$ a $28 \%$ de los casos ${ }^{1}$.

La infección micótica rinosinusal no invasora es la forma clínica más frecuente en el hospedero inmunocompetente y su espectro incluye: bola fúngica, sinusitis crónica erosiva y rinosinusitis fúngica alérgica ${ }^{2}$.

En Chile, se ha comunicado Scedosporium como causa de infección pulmonar y de rinosinusitis por Pseudallescheria $\mathrm{sp}^{3,4}$ e infección de herida operatoria por Scedosporium prolificans ${ }^{5}$.

Reportamos una infección rinosinusal por Scedosporium apiospermum en un paciente inmunocompetente.

\section{Caso clínico}

Paciente con 47 años de edad, sin antecedentes mórbidos mayores; a los 27 años de edad le fue extirpado un cuerpo extraño (cuesco de cereza) de la fosa nasal derecha. Consultó por cuadro de aproximadamente cinco años de evolución consistente en descarga posterior recurrente, muco-purulenta con restos hemáticos, sin respuesta a terapia antibacteriana. Al examen físico destacaba la desviación del tabique nasal a derecha, sin otros hallazgos patológicos. El estudio imagenológico con radiografía de cavidades paranasales mostró opacidad del seno maxilar derecho y la TAC de cavidades paranasales fue informada como: "seno maxilar derecho ocupado por material con densidad de tejidos blandos, presencia de burbujas de gas, con extensión hacia el canal osteo-infundibular y levemente hacia la fosa nasal ipsilateral, ensanchamiento y remodelación ósea del canal infundibular, sin evidencias de erosiones" (Figura 1). La naso-fibro-broncoscopia detectó una lesión polipoidea en la fosa nasal derecha a la altura del meato medio, hacia posterior, sin alcanzar la coana, vascularizada. En la rinofaringe se apreciaba tejido adenoideo de aspecto normal. La orofaringe e hipofaringe tenían aspecto normal. Exámenes de laboratorio destacables: hemograma con hemoglobina $12,5 \mathrm{~g} / \mathrm{dl}$, leucocitos 4.500 céls $/ \mathrm{mm}^{3}$ (eosinófilos $2 \%$, segmentados $58 \%$, linfocitos $31 \%$ y monocitos $8 \%$ ), plaquetas 312.000 céls $/ \mathrm{mm}^{3}$, VHS $44 \mathrm{~mm} / \mathrm{h}$.

Se le realizó cirugía de remoción del contenido sinusal mediante técnica de Caldwell-Luc, con una incisión por el reborde alveolar superior derecho y apertura de una ventana ósea en el seno maxilar, dando salida a secreción negruzca barrosa de gran cantidad. No se encontró lesiones de la fosa nasal derecha ni tejido adenoideo anómalo en las coanas o rinofaringe. Evolucionó en forma satisfactoria en el post-operatorio. El material obtenido fue enviado a estudio microbiológico e histopatológico. El informe anátomo-patológico fue: "sinusitis crónica
Hospital San Juan de Dios, Santiago, Chile Servicio de Medicina Interna, Unidad de Infectología (LCC) Laboratorio de Microbiología (LCC, CTP)

Servicio Otorrinolaringología (LRW) Servicio de Anatomía Patológica (CMS)

Universidad de Chile, Facultad de Medicina Occidente

Departamento de Medicina Interna (becaria) (CGR)

ICBM, Programa de Microbiología y Micología, Laboratorio de Micología (CTP)

Universidad Mayor,

Santiago, Chile Facultad de Medicina Laboratorio de Micología (VSV)

Fuente de apoyo financiero: no hubo

Recibido: 19 de agosto de 2008 Aceptado: 23 de marzo de 2009

Correspondencia a: Leonardo Chanqueo Cornejo Ichanqueo@gmail.com 


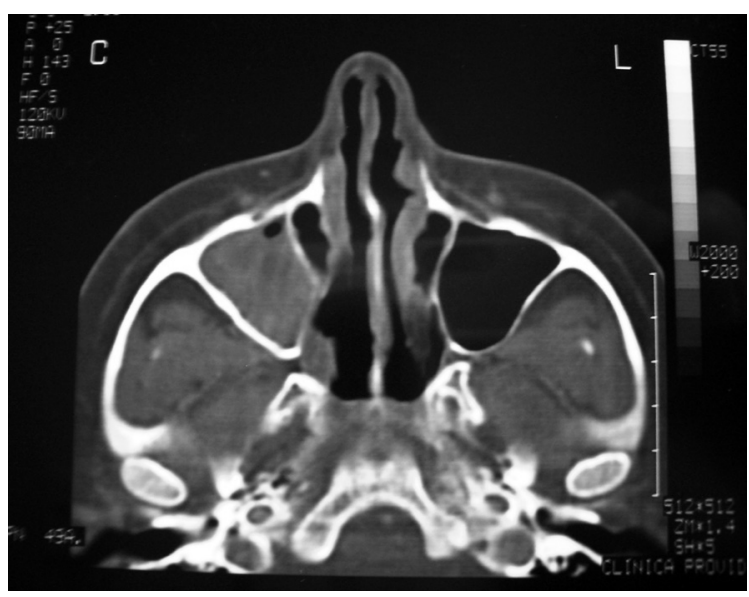

Figura 1. Seno maxilar derecho ocupado por material con densidad de tejidos blandos, presencia de burbujas de gas, con extensión hacia el canal osteo-infundibular y levemente hacia la fosa nasal ipsilateral.

erosiva, presencia de hongo filamentoso con hifas hialinas septadas y ramificadas, sugerente de Aspergillus sp. No se observó invasión micótica ni atipias". (Figuras 2a y 2b). Se aisló un hongo filamentoso de crecimiento rápido a $25^{\circ} \mathrm{C}$, con colonias de textura aterciopelada a algodonosa, de color crema a café canela, bordes irregulares y con un leve pigmento café (Figura 3a). Microscópicamente se observó la presencia de hifas hialinas septadas con conidióforos rectos, de largo variable con generación en su porción distal de aneloconidio unicelular oval y base trunca (Figura 3b), que fue identificado como S. apiospermum, forma anamorfa o asexuada de Pseudallescheria boydii. Se confirmó la identificación en el Laboratorio de Micología del Instituto de Ciencias Biomédicas (ICBM), Facultad de Medicina, Universidad de Chile.

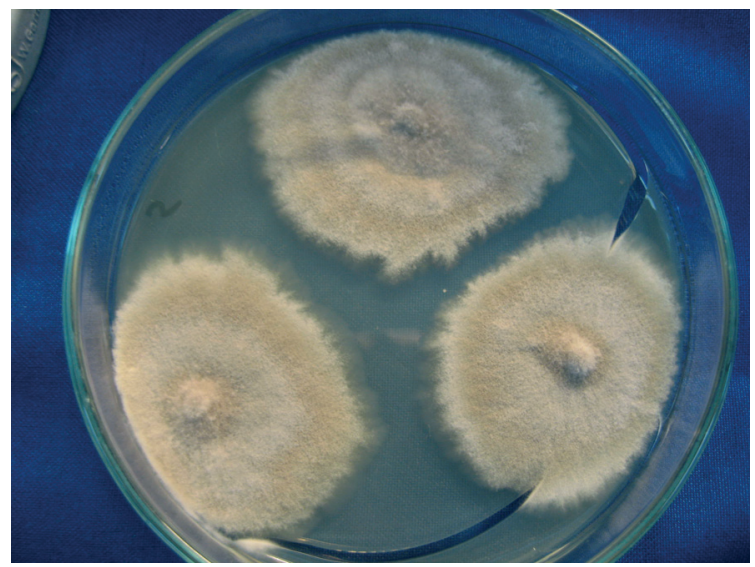

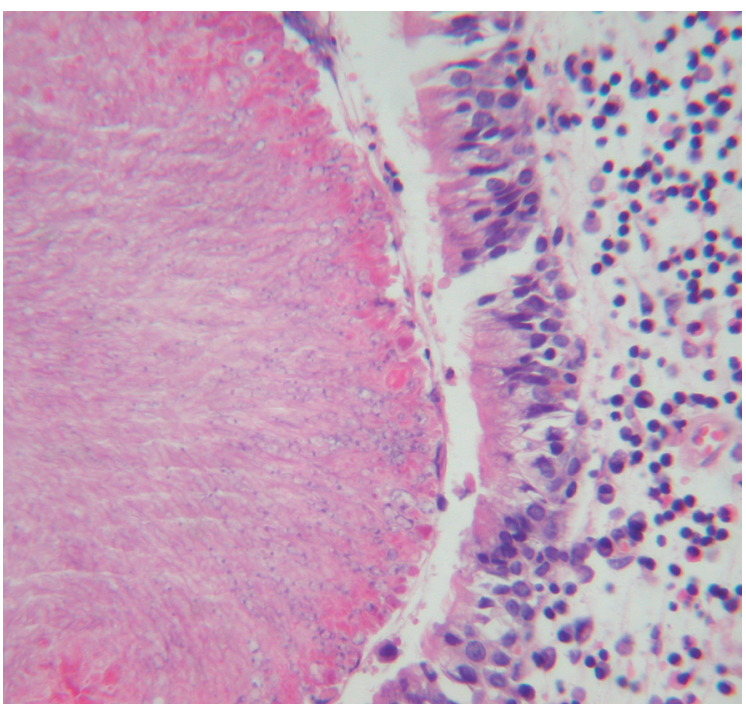

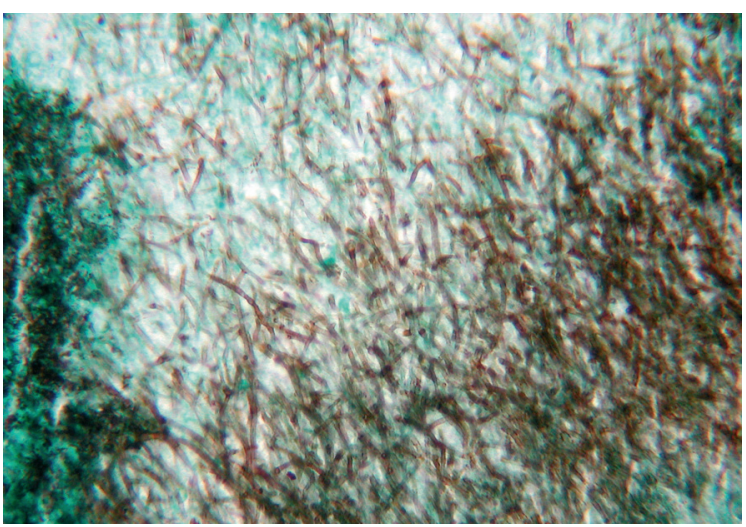

Figura 2. Bola de hongos rodeada de inflamación supurada (tinción con hematoxilina-eosina) (a); bola de hongos (tinción GromoriGrocott) (b).
Figura 3. Hongo filamentoso con colonias de textura aterciopelada a algodonosa, de color crema a café canela con bordes irregulares (3a) Hifas hialinas septadas con conidióforos rectos, de largo variable con generación en su porción distal de aneloconidio unicelular oval y base trunca (3b).

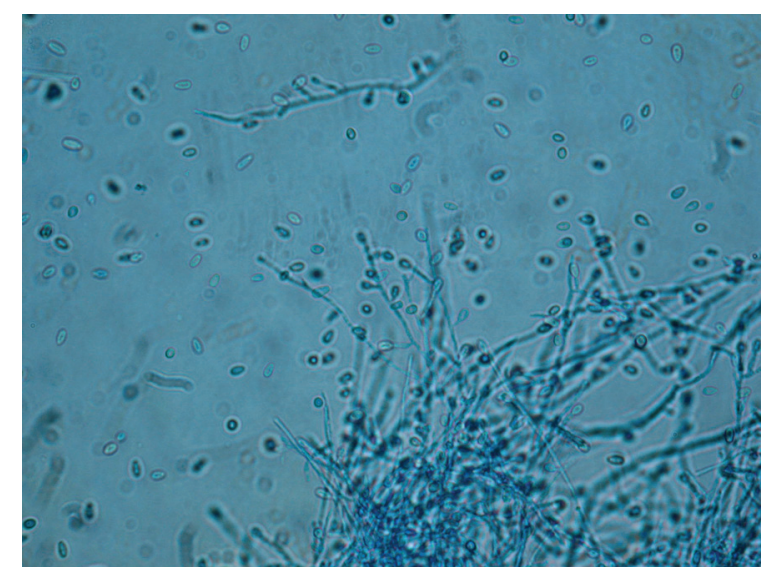

Rev Chil Infect 2009; 26 (5): 453-456 
Dada su larga evolución sintomática y la sospecha de una lesión polipoidea de tipo invasora se dejó inicialmente tratamiento antifúngico con $200 \mathrm{mg}$ de itraconazol cada 12 horas, siendo bien tolerado, sin alteración de las pruebas hepáticas, el que fue suspendido al no evidenciarse compromiso micótico invasor en la biopsia.

La evolución clínica a tres meses plazo fue satisfactoria; una nueva TAC de cavidades paranasales mostró su total neumatización y simetría, signos de maxilectomía medial derecha y elementos inflamatorios marginales con pequeño nivel hidro-aéreo del seno maxilar derecho.

\section{Discusión}

Las rinosinusitis fúngicas se producen por una respuesta del hospedero frente a la colonización y/o invasión fúngica de las cavidades paranasales. Actualmente se clasifican en formas invasoras y no invasoras (también denominadas extra-mucosas), basado en la invasión micótica de los tejidos, ya fuera en mucosas, vasos sanguíneos o hueso. Las formas no invasoras son más frecuentes, pudiendo presentarse como bola fúngica (antiguamente mal denominado micetoma rinosinusal) o rinosinusitis fúngica alérgica ${ }^{1,6}$.

El caso expuesto correspondió a una infección rinosinusal compatible con bola fúngica, clínicamente caracterizada por descarga posterior recurrente, refractaria a la antibioterapia y con compromiso unilateral. Posiblemente el antecedente remoto de un cuerpo extraño nasal fue la puerta de entrada del hongo hacia las cavidades paranasales y el posterior desarrollo de una bola fúngica.

Se describe que la bola fúngica en cavidades paranasales se presenta más frecuentemente en población de mayor edad y en mujeres ${ }^{7}$. Los cultivos microbiológicos son habitualmente negativos, sólo en 23 a $50 \%$ de los casos se logra desarrollo micótico, hecho que se atribuye a una pobre viabilidad de los hongos al interior de la bola fúngica $^{1,8}$. El hongo identificado con mayor frecuencia, considerando cultivo y técnicas de biología molecular, es Aspergillus fumigatus ${ }^{7,9,10}$; otros hongos ocasionalmente encontrados son $S$. apiospermum (P. boydii), Aspergillus flavus, Aspergillus niger y Aspergillus terreus ${ }^{1}$.

Sin embargo, se debe considerar que este hongo crece bien en agar Sabouraud glucosa, agar sangre y agar chocolate, siendo recomendados medios selectivos, como agar Leonian modificado o agar ciclo-heximida, cuando se trabaja muestras respiratorias, que pudiesen contener otros hongos de más rápido crecimiento ${ }^{11}$.

Los microorganismos del género Scedosporium corresponden a hongos filamentosos que ocasionalmente se aíslan de infecciones en el ser humano ${ }^{11,12}$, siendo las sinusitis fúngicas causadas por este oportunista inusuales; escasísimos casos han sido reportados, considerándosele un patógeno oportunista ${ }^{4,13,14}$. Las especies de importancia médica son $S$. apiospermum, y S. prolificans. Scedosporium apiospermum es un hongo de distribución mundial que puede cultivarse a partir de muestras procedentes del suelo, tierra de macetas, alcantarillas, aguas estancadas, arroyos y estiércol ${ }^{11}$.

Las patologías causadas por este oportunista van desde la colonización y reacciones alérgicas hasta infecciones localizadas y diseminadas; estas últimas pueden ser infecciones de piel y tejidos blandos, meningitis o absceso cerebral, artritis, osteomielitis, endocarditis, endoftalmitis y otras $^{12,15}$. Las infecciones diseminadas son más frecuentes en pacientes inmunodeprimidos, especialmente en neutropénicos y aquellos que han sido sometidos a trasplantes de órganos sólidos o de precursores hematopoyéticos ${ }^{16}$.

Histológicamente las especies Scedosporium sp y Aspergillus sp son similares. Su cultivo es imprescindible para diferenciar entre ambos, de acuerdo a las características macroscópicas y microscópicas del hongo. Sin duda, el hallazgo en cultivo nos permitió llegar a un diagnóstico etiológico, que no hubiese sido posible sólo con la histología, dada lo inespecífico de su presentación clínica y del aspecto histológico.

No existen series controladas en relación al tratamiento de la bola fúngica; actualmente se recomienda su resolución quirúrgica mediante la técnica de Cadwell-Luc, la que incluye remoción de todo el material fúngico ${ }^{1}$.

Los pacientes inmunocompetentes no requieren terapia adyuvante local o tratamiento con antifúngicos sistémicos, fármacos que sí se recomiendan en pacientes inmunocomprometidos. En caso de recurrencia o persistencia de la sintomatología, así como también en pacientes inmunocomprometidos, se requiere un estrecho seguimiento clínico y endoscópico. En el caso que presentamos se emprendió este seguimiento. Dada la evolución clínica y la ausencia de factores que hicieran pensar en inmunodepresión no se solicitó un estudio inmunológico más específico, asumiendo que correspondió a una infección localizada en un hospedero inmunocompetente. La posibilidad de progresión de la bola fúngica a enfermedad invasora en inmunocompetentes es remota y no ha sido bien documentada.

El antifúngico recomendado en pacientes que lo requieran -habitualmente infecciones invasoras u hospederos inmunocomprometidos- y la duración del tratamiento, aún son controvertidos. Los datos de susceptibilidad in vitro muestran actividad antifúngica de los azoles (salvo fluconazol y ketoconazol), siendo el más potente voriconazol, y también de las equinocandinas (caspofungina y anidulafungina). No tienen actividad antifúngica contra Scedoporium sp, terbinafina y 5 - fluocitosina; anfotericina B ejerce una actividad limitada ${ }^{17-19}$.

En resumen, se debe sospechar el diagnóstico de bola fúngica frente a cuadros de infección rinosinusal unilateral 
recurrente con imágenes compatibles. Es fundamental el envío de muestras a estudio histopatológico para evaluar la invasión micótica de la mucosa y a estudio microbiológico para la identificación micológica adecuada de hongos emergentes.

\section{Resumen}

Las infecciones por Scedosporium sp pueden traducirse en colonización, infecciones localizadas superficiales y profundas, o enfermedad diseminada. Presentamos un caso clínico de infección rinosinusal por Scedosporium apiospermum en una paciente de 47 años, con antecedente de cirugía por cuerpo extraño en la fosa nasal derecha. Consultó por descarga posterior muco-purulenta y recurrente, sin respuesta a tratamiento antibacteriano. Las imágenes de cavidades paranasales mostraron opacidad del seno maxilar derecho. Se realizó cirugía de remoción de contenido sinusal cuyo estudio histológico reveló sinusitis crónica erosiva, colonias de hongos con morfología sugerente de hongo filamentoso y desarrollo de $S$. apiospermum en el cultivo.

\section{Referencias}

1. - Grosjean P, Weber R. Fungus balls of the paranasal sinuses: a review. Eur Arch Otorhinolaryngol 2007; 264: 461-70.

2. - Uri N, Cohen-Kerem R, Elmalah I, Doweck I, Greenberg E. Classification of fungal sinusitis in immunocompetent patients. Otolaryngol Head Neck Surg 2003; 129 (4): 372-8.

3.- Oddo D, Lobos T, González A, Fardella C. Pseudoallescheriasis pulmonar no invasiva. Un caso con diagnóstico histopatológico y micológico en material obtenido por broncoscopia. Rev Méd Chil 1985; 113 (10): 999-1003.

4.- Pruzzo E, Labarca J, Gúzman A, León P, Emmerich M, Bustos, Rico B. Rinosinusitis por Pseudoallescheria boydii: caso clínico. Rev Otorrinolaringol Cir Cabeza Cuello 2000; 60: 109-16.

5.- Díaz M, Juliet C, Monzón A, RodríguezTudela J. Absceso de herida operatoria por Scedosporium prolificans: Primer aislamiento en Chile. Revisión de la literatura. Rev Chil Infect 2004; 21 (1): 65-9.

6.- Fonseca X, Fernández F. Rinosinusitis fúngica alérgica: Revisión. Rev Otorrinolaringol Cir Cabeza Cuello 2005; 65: 45-54.

7.- Ferreiro J, Carlson B, Cody D T. Paranasal sinus fungus balls. Head Neck 1997; 19(6): 481-6.

8.- Dufour X, Kauffmann-Lacroix C, Ferrie J, Goujon J, Rodier M, Klossek J. Paranasal sinus fungus ball: epidemiology, clinical features and diagnosis. A retrospective analysis of 173 cases from a single medical center in France, 19892002. Med Mycol 2006; 44 (1): 61-7.

9.- Karci B, Burhanoglu D, Erdem T, Hilmioglu S, Inci R, Veral A. Fungal infections of the paranasal sinuses. Rev Laryngol Otol Rhinol (Bord) 2001; 122 (1): 31-5.

10.- Willinger B, Obradovic A, Selitsch B, BeckMannagetta J, Buzina W, Braun H, et al. Detection and identification of fungi from fungus balls of the maxillary sinus by molecular techniques. J Clin Microbiol 2003; 41 (2): 581-5.

11.- Sybren G, Vitale R. Bipolaris, Exophiala, Scedosporium, Sporothrix and other Dermatiaceous Fungi. Murray P, Baron E, Jorgensen J, Landry M, Pfaller M, editors. Manual of Clinical Microbiology, $9^{\text {th }}$ Ed. Washington: ASM Press; 2007, pp 1899-1915.

12.- Cortez K, Roilides E, Quiroz-Telles F, Meletiadis J, Antachopoulos C, Knudsen T, et al. Infections caused by Scedosporium spp. Clin Microbiol Rev 2008; 21: 157-97.

13.- Bates D, Mims J. Invasive fungal sinusitis caused by Pseudallescheria boydii: case report and literature review. Ear Nose Throat J 2006; 85 (11): 729-37.

14.- Winn R, Ramsey P, McDonald J, Dunlop K. Maxillary sinusitis from Pseudallescheria boydii. Efficacy of surgical therapy. Arch Otolaryngol 1983; 109(2): 123-5.

15.- Cooley L, Spelman D, Thursky K, Slavin M. Infection with Scedosporium apiospermum and S. prolificans, Australia. Emerg Infect Dis 2007; 13 (8): 1170-7.

16.- Husain S, Muñoz P, Forrest G, Alexander B, Somani J, Brennan K, et al. Infections due to Scedosporium apiospermum and Scedosporium prolificans in transplant recipients: clinical characteristics and impact. Clin Infect Dis 2005; 40: 89-99.

17. - Alastruey-Izquierdo A, Cuenca-Estrella M, Monzón A, Rodríguez-Tudela J. Prevalence and susceptibility testing of new species of Pseudallescheria and Scedosporium in a collection of clinical mold isolates. Antimicrob Agents Chemother 2007; 51: 748-51.

18.- Pastor F J, Guarro J. The role of voriconazole in the treatment of emerging mycoses. Rev Iberoam Micol 2007; 24: 228-32.

19. - Fica C A. Tratamiento de infecciones fúngicas sistémicas Primera parte: fluconazol, itraconazol y voriconazol. Rev Chil Infect 2004; 21 (1): 26-38. 